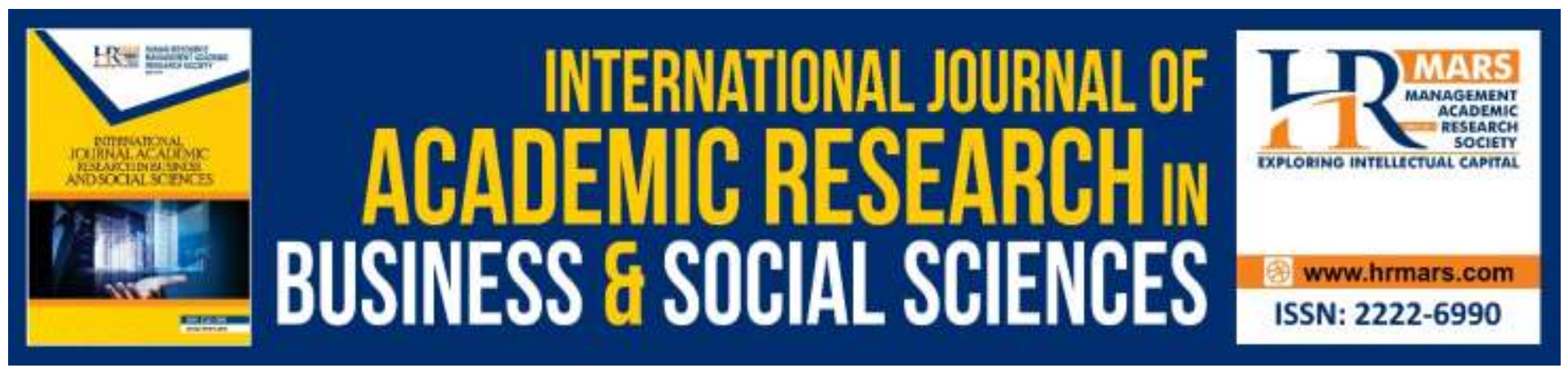

\title{
Determinants of the Production System Time (JIT) on Reduce Waste: Case Study in a Salsal Water Company
}

Mohammed Alhamdi, Alhamzah Alnoor, Bilal Eneizan, Mostafa Abdulla, Aymen Raheem Abdulaali

To Link this Article: http://dx.doi.org/10.6007/IJARBSS/v9-i7/6088

DOI: $10.6007 /$ IJARBSS/v9-i7/6088

Received: 22 May 2019, Revised: 01 June 2019, Accepted: 22 June 2019

Published Online: 13 July 2019

In-Text Citation: (Alhamdi, Alnoor, Eneizan, Abdulla, \& Abdulaali, 2019)

To Cite this Article: Alhamdi, M., Alnoor, A., Eneizan, B., Abdulla, M., \& Abdulaali, A. R. (2019). Determinants of the Production System Time (JIT) on Reduce Waste: Case Study in a Salsal Water Company. International Journal of Academic Research in Business and Social Sciences, 9(7), 17-32.

Copyright: (C) 2019 The Author(s)

Published by Human Resource Management Academic Research Society (www.hrmars.com)

This article is published under the Creative Commons Attribution (CC BY 4.0) license. Anyone may reproduce, distribute, translate and create derivative works of this article (for both commercial and non-commercial purposes), subject to full attribution to the original publication and authors. The full terms of this license may be seen

at: http://creativecommons.org/licences/by/4.0/legalcode

\section{Vol. 9, No. 7, 2019, Pg. 17 - 32}

Full Terms \& Conditions of access and use can be found at http://hrmars.com/index.php/pages/detail/publication-ethics 


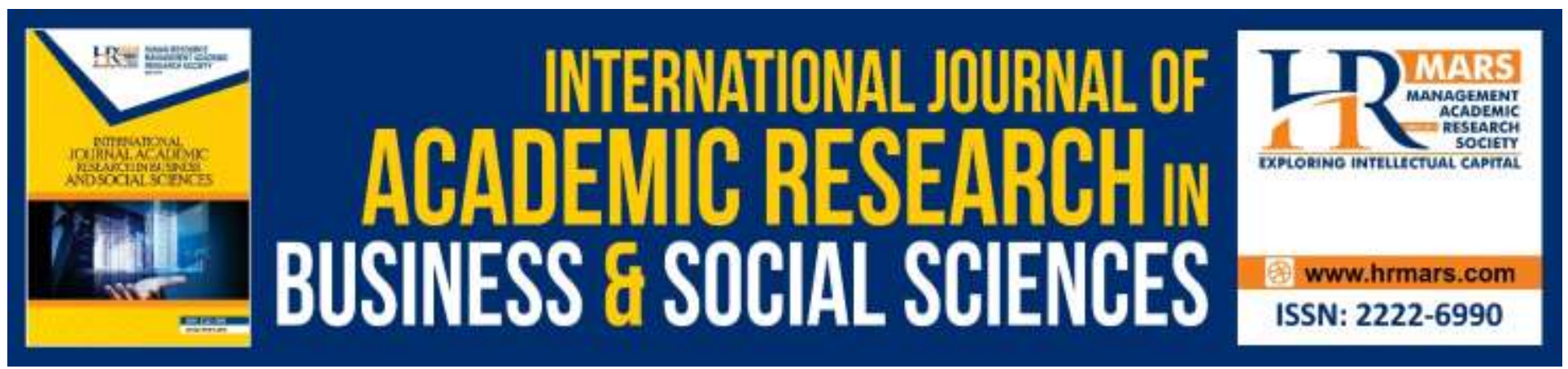

\title{
Determinants of the Production System Time (JIT) on Reduce Waste: Case Study in a Salsal Water Company
}

\author{
Mohammed Alhamdi \\ Universiti Malaysia Kelantan, Malaysia
}

\author{
Alhamzah Alnoor \\ Management Technical College, Southern Technical University, Iraq \\ Bilal Eneizan
}

Faculty of Economics and Business, Jadara University, Jordan

\author{
Mostafa Abdulla, Aymen Raheem Abdulaali \\ Management Technical College, Southern Technical University, Iraq
}

\begin{abstract}
This study aimed to identify the effect of the production system on time to maximize the profitability of industrial companies through (reducing production costs, improving product quality, reducing damage rates, achieving competitive advantage and reducing time factor). This study attempted to answer the following questions: How do I apply the production system on time in a metal water chain from the point of view of the study sample? What is the application of the production system on time in maximizing the profitability of a mineral water chain? The sample community included all the workers in the mineral water chain and was deliberately chosen from among the companies because it enjoys a large capital compared to other companies. The number of employees (800) employees and employees who work in the productive departments and marketing departments and quality management and the total maintenance of the population has been selected a sample of (205) employees and staff was chosen proportionately. In order to achieve the objectives of the study, we prepared a questionnaire covering (28) paragraphs as final To answer the second question, we used the arithmetic averages and the standard deviations. The application of the production system on time in a company of mineral water requires The development of production processes through several requirements, including relying on a specified number of suppliers and the establishment of a system of quality control and automation of production lines The development of administrative and cost accounting systems through several requirements including the development of a system of
\end{abstract}


cost in reverse and the need to use the basis of allocation of costs The implementation of the production system on time contributes to reducing the size of the stock by reducing the amount of money invested in the inventory and reducing the risks resulting from the damage and obsolescence of the stored materials.

\section{Introduction}

The sector of industrial companies is one of the important and vital sectors in the economies of countries. This sector has witnessed a great development and progress in the field of manufacturing, production and accounting methods that are used especially in light of the continuous changes in the business environment and the increasing competition between companies. Recent trends in the methods and techniques of accounting and management used from the most important indicators that indicate their relationship to changes in the business environment and its efforts to improve their performance in order to increase their competitiveness through the adoption of those technologies, and perhaps the most important The modern intentions, which have become increasingly popular in recent times, are the technology of the production system on time Just In Time, although the idea of its application dates back to the seventies of the last century, where the first dish of this system is the Japanese Toyota 196 (Al-Abrrow et al., 2018; Abdulaali et al., 2019). Its success in its implementation has contributed to its spread in many companies around the world, especially the industrial ones, due to the advantages and advantages achieved by that application in improving and improving the performance of companies through the optimal exploitation of its lights and reducing production costs and achieving overall productivity and creating added value, In improving their profitability Increasing their competitiveness. This study aims at identifying the role of implementing the production system in a timely manner in enhancing the financial performance of the industrial companies by knowing its role in improving the performance of the financial companies of these companies especially liquidity indicators, profitability, activity, And debt, which is one of the most important indicators that reflect the ability of the enterprise to manage the assets and resources and ability to improve investment returns and improve investment opportunities (AlAbrrow et al., 2019). which in turn reflected in increasing their competitiveness, especially in light of the impact of these companies changes in The business environment and the increasing competition in the products and goods offered and its pursuit to keep pace with those changes in the business environment, in order to enhance and improve its financial performance (Eneizan \& Obaid, 2016; Abdulaali, 2018).

\section{Research Problem}

The complexity of production processes and changes in the business environment require industrial companies to search for new cost systems to help them reduce production costs on the one hand, and raise the quality of their production on the other.

Therefore, the elements of the study problem can be formulated in the following question:

1. What is the nature of the relationship between the production system (JIT) and the reduction of production costs. 


\section{Research Importance}

The importance of the study stems from the importance of the system of production on time (JIT), which is a modern technology that has increased interest in its application by companies in the recent period due to the many advantages and advantages achieved by that application, and linking that application to enhance its financial performance by knowing its role in Enhancing their efficiency, improving their profitability and enhancing their ability to pay their short and long-term obligations.

\section{Research Goals}

The main objective of this study is to uncover the reasons that lead to the non-application of the production system (lean production) in the industrial companies by achieving the following objectives:

1. Explain the concept of production and the usefulness of its application in industrial companies

2. Identify the problems facing the application of the production system, in a metal water chain

3. Preparation of a theoretical framework for this study, through the study of contemporary literature related to the study, and identify the intellectual content to come up with useful indicators of the current study

4. Try to reach practical or practical results, which lead to the development of a system of mineral water chain, through the submission of recommendations and suggestions useful for that

5. This study should be the beginning of other studies on the obstacles to the application of the system of production in other industrial sectors and finding solutions.

\section{Hypotheses of the Study}

The main hypothesis of the study is:

Is there a statistically significant effect of the application of the JIT in reducing the costs of production in a mineral water treatment plant?

\section{Theoretical Framework}

\section{Concept Production System (JIT)}

Although the system of production on time of the technologies that emerged in the early seventies and has been a great success in the application of many companies, but there is no specific definition of the system of production on time, but all definitions are consistent in terms of philosophy and content:

(Kootanaee et al., 2013) defined the system of production in time as a system that works to purchase materials for the process of production and production in quantity and time specified according to customer needs (Eker \& Pala, 2008). was defined as a system that relied on The concept of continuous development in the production process to achieve the ease and smoothness in the production process by relying on the production of small batches in quantity and time limit (Al Matarneh, 2012). is a system designed to reduce waste and reduce waste in the production process by optimizing the production elements and reducing their cost by eliminating the unnecessary activities that accompany the production process and which increase the cost of production (Krajewski et al., 2013). It is a philosophy of excellence related to the development of the inventory policy affected and 
demand, which leads to production according to the specifications set, and the rate of delivery fast, and without unused stock, and without waiting time is not necessary (Eneizan \& Wahab, 2016). It has been defined as a production system of the required quantity. It is built on the basis of strict inventory control, with an information system, and a precise order between production processes and suppliers, so that the orders reach their specifications, quantities and exact time in a stable environment. It is the provision of efficient products, delivery of necessary parts and quantities required, and at the right time and place using the minimum facilities (Akomeah et al.,2018). It is a system that depends on the purchase, production and delivery on time based on the needs of customers in order to reduce inventory cost and other unnecessary costs during the production process so that the organization is able to achieve competitive advantage. It is a technology-based approach to reduce waste at the time of purchase and production, and to dispense with all kinds of inventory in a way that reduces the cost of the production process and meet the needs of customers in a timely manner or in the appropriate quantities. Adeyemi (2010) defines it as a system that acts as a comprehensive strategy that combines key tactical elements, including procurement and production, to eliminate waste and optimize the use of resources throughout the supply chai (Amgar, 2008). It is a regular entrance to improve overall productivity and eliminate waste sources and aims to achieve production at the lowest cost and deliver the necessary quantities of finished products with the required quality at the specified time and place without submission or delay. Al-Gamal and Noureddine (2008) defined it as the system that is produced in each part of the product at one of the operating stations on the production line at the same moment as the next station, which is ready to be received and the client's request for the product is a starting point for all operations On the production line in the reverse sequence of the harmonized and disciplined harmony between the centers and operating stations, the aim is to ensure the flow of products in proportion to the customer's demand and achieve a reduction in inventory level. 


\section{Production System Targets on Time (JIT)}

The main objective of JIT is to produce quality products in a timely manner and at the right place at the lowest cost, in order to achieve the competitive advantage of the organization and maximize its profitability (Al-Matarneh, 2012). that the goal of the application of the system of instantaneous production is:

- Eliminate surplus production, production is the same demand.

- Eliminate standby time, reduce boot time and reboot.

- Eliminate or avoid defective production through continuous improvement of quality control system.

- Reduce inventory to the minimum, as long as production is linked to demand.

- Focusing on the processes produced only, and minimizing unnecessary and unnecessary movements.

\section{Benefits and Advantages of Using the Production System on Time}

Although the JIT system is fully implemented, the benefits gained from its application are not oneoff, but are gradually taken advantage of (Krajewski et al., 2013).

-Production with better quality and greater quality.

-The quality of production becomes the responsibility of each worker and not the responsibility of quality inspectors only.

- Access to damage and waste to zero.

- Reduce the cycle of the product in the production processes by eliminating unnecessary activities that hinder the production process.

- Flow and flow in the production process.

- Inventory access to zero.

The lean production system is a new philosophy that introduces new concepts and methods of production, helps efficiently to achieve a competitive position among companies in international markets. The strength of the production system shows that the concepts that have been introduced have changed concepts and principles, Where it has been widely recognized for its efficiency in removing all kinds of waste, reducing inventory, scheduling production and quality, and establishing new relationships with suppliers. He added that the production system on time achieves many benefits in different fields, which are reflected in reducing inventory and increasing productivity, by reducing deadlines, reducing rejection rate, responding rapidly to customers' requests, saving in costs, Reducing the required areas for production and storage operations, reducing inventory, increasing the use of equipment, in addition to developing the skills of the employees because of the variety of tasks required of them, and the lack of feeling of boredom due to routine work (Krajewski et al., 2013). The system application has many advantages that make it a powerful competitive weapon having demonstrated the ability to influence strategic performance: cost, quality, flexibility, reliability as a comprehensive and integrated vision of the production system in its broadest sense, from suppliers, And customers whose demand represents the production function in this system. Therefore, the application of the production system on time reduces costs and improves revenue (Alnoor et al.,2019). 


\section{Elements of the Production System on Time (JIT)}

The components of the implementation of the production system on time and through the return of this study to many sources and references that dealt with these elements, it can be identified as follows:

目 Buy in time.

? Output stop for the drag road.

? Reduce inventory to a minimum.

? The internal structure of the plant.

1. Purchasing in a timely manner: Under the implementation of the production system on time, the raw materials required for the production process are purchased in quantity and time. The company initially depends on determining the required requirements and the appropriate specifications, and then determining the appropriate purchase quantity according to the demands of its customers (Singh and Garg, 2011). The acquisition of the company in a timely manner requires the establishment of long-term relations with its suppliers and the creation of a climate of trust between them in a manner that helps to supply materials for the process of production in quantity, time and quality required (Amoako et al., 2017).

2. Production according to the Pull method: Under the production system on time, the output flows in what is described as the entrance of the products. The last stage of the production sends a reference to the previous production point by the amount of materials or pieces needed to assemble the products within the few hours This amount of material or pieces is needed to assemble the products within the next few hours. This amount of materials or pieces is only supplied, and the same signal is sent back to each previous production point in a manner that keeps the flow and flow of materials easily and without stock at the In this approach, a particular production point ends its operations on the payment of the output paid to the next production point Regardless of whether this point is ready to be received or not. The result is an unnecessary increase in inventory of incomplete products at this point, which may not be used and work on them for days or even weeks, resulting in freezing funds and inefficient operations (Alnoor et al., 2019). Illustrate the difference between the two systems of attraction and payment used by the production system on time and which aims to reach the zero stock while.

3. Reduction of inventory to the minimum: The company must maintain various types of inventory, which are borne by many costs, such as retention costs, capital costs invested in the inventory in addition to the cost of insurance and protection and storage, contrary to administrative expenses (Husin et al., 2019) These costs are especially high when the company has an excess stock, and this is due to five factors as it comes (Ho, 2008).

When the production system is implemented on time, these reasons disappear due to their dependence on the supply of raw materials needed for the production process in quantity and in a timely manner, reducing the preparation time and the production of small batches according to customer needs. The stock is minimized to zero stock or zero inventory, which is based on reducing inventory to zero through the flow of raw materials when needed, and the delivery of finished products to customers directly. The stock is empty Both types of raw materials or manufactured or finished products avoid many costs and risks arising from the company's retention of such types of inventory as transport, storage, protection and other costs (Babagana et al., 2019). 
The researcher believes that reducing the stock to the lowest possible level is one of the essential elements of the implementation of the production system on time and that the company's access to the lowest possible reduction in the stock depends on the ability to implement the other components of that system, especially to establish close relationships with suppliers can supply materials Raw materials needed for the production process on time. The greater the company's ability to establish close and good relationships with its suppliers at the same time, the greater its ability to know the needs of its customers and to meet those needs as the ability to reduce the stock to the lowest possible degree.

\section{Factory Internal Order}

The implementation of the production system on time requires the improvement, development and arrangement of the production flow lines in the plant. The flow of production can be defined as: (a) the path taken by the product as it moves through manufacturing processes from the time the material is received until it is fully shipped. The companies used to design the plant so that all the similarities are put together In the sense of having all the perforation equipment in one place and all the forming equipment in another, which requires the movement of production from one of the groups of machines to another group may be in the same building or may be in another building, and the result is an increase in handling costs and the need for a large volume of The stock is under and running Incomplete production When moving from one point of production to another, according to this system, all the machines needed to produce a particular product are put together in one place, thus dividing the large groups of similar devices to result in several production flow lines (Krajewski et al., 2013) Optimized for the factory according to the production system specified by U-shaped design where the flow of the product in the form of character, which is characterized by easy communication between the team so close to each other to allow the opportunity for workers to move and thus reduce the preparation time.

\section{Small Size of Payments}

The production system in a timely manner is based on the production of small batches, reducing the time of preparation and ventilation and purchase of raw materials for the process of production in quantity and time, and production according to the needs of customers contributes to the production of small batches based on those needs, and this helps to reduce the inventory and costs Transport and handling also helps to detect the damage quickly and limit the excess (Alnoor et al., 2019).

\section{Relationship with Suppliers}

Under traditional trends, supplier relations are governed by short-term considerations of conflict. The buyer sees from the supplier that he is seeking the greatest possible profit. The buyer is trying to shop from more than one source, working on the best deals, Obtain the required specifications, especially that the suppliers in case of not sure about the required items and the size of the order and the time of receipt of the order and the possibility of repeating the order in this atmosphere is the general atmosphere between the buyer and the supplier hostile atmosphere, but under the modern trends of the system of production in time The purchaser assumes that there is a common interest. The buyer wishes to find a supplier to achieve the best conditions, ie, a specific demand for 
reliable quality elements with repeated delivery of small quantities and reasonable cost. If the buyer finds that supplier, it is regarded as the sole source of supply and signs a long term contract to ensure stability. Atmosphere of cooperation to achieve common interest (Eker \& Pala,2008).

\section{Customer Focus}

The attention to customers is considered the strength behind quality, improving the productivity and success of the company and this interest is not only to meet the customer's demand through production and delivery of the required specifications in a timely manner but to represent their wishes and ensure their future needs. This will serve the company in the development of future plans for production according to customer demand and create loyalty and belonging between The client and the company, and giving employees the opportunity to deal with them directly, they can identify their needs and expectations and this leads to the identification of the problem of quality and production by the customers, through follow-up with them, which enhances their understanding and awareness of the quality (Krajewski et al., 2013).

\section{Workers with Diverse Skills}

The application of the production system on time requires the availability of highly qualified workers and multiple skills so that there is flexibility in the movement of any worker from one job to another especially in the absence of a worker in a manner that prevents the interruption of work and also requires the system to work on the development of workers in a manner that prevents the interruption of work as required by this system Work on developing employees constantly to deal with any changes occurring in the techniques and methods used, as well as work to motivate them to participate in the decision making and give them some powers that allow them the possibility of conducting some minor maintenance that enables them to carry out repairs and maintenance Linnaean (Kootanaee et al., 2013).

\section{Preventive Maintenance}

In the traditional manufacturing systems, the cost of maintenance of faults on two types includes the cost of repairing equipment or idle equipment, including the cost of workers and spare parts, etc. The second type is the cost of the effects caused by faults, including the cost of indirect work used during faults and the additional time required to meet the production schedule, And the cost of losing the reputation of the company and the inability to meet the demands on time and to face all these problems in the traditional system is to keep the excess stock, between the preventive maintenance in the production system in time is to avoid the breakdown of machines to prevent the machines from stopping the uncle This requires that the company have machines that have high efficiency in determining specific timetables for periodic and preventive maintenance, in order to prevent any malfunction. In machines, so as not to conflict with delivery dates of customers or occur in a delay and the machines are on the degree of flexibility so that it can be used to accomplish multiple tasks instead of a single process and thus the existence of several products in the production line instead of a single product (Haddad et al., 2019). 


\section{Avoid Defective and Damaged}

The production system at the specified time to avoid production is not conforming to specifications according to customer request and avoid damage and defects in the process of production, and there are many types of damage and exhaust, which can be avoided through the implementation of the production system on time and noted (Thürer et al., 2014) To it as follows:

1. The damage caused by the increase in production, which is the increase in production without demand.

2. The damage caused by the increase in production, which is the increase in production without demand.

3. The result of the wait is waiting for the worker when the previous production plant cannot finish the work in time and wait for a certain worker to disable the machine that works until the arrival of the maintenance worker.

4. The combination that accompanies transportation and this results in the non-placement of tools and parts in the place allocated in the right form leads to an increase in energy and expenses.

5. Inventories resulting from the inventory. The production system on time is considered to be a major waste of storage, as the company's retention of large quantities of inventory increases costs.

\section{Total Quality}

Total Quality is defined as an administrative philosophy and an organized science curriculum that includes the implementation of the plans in the best way, with the commitment of continuous improvement and development, the participation of all employees and the integration of quality to achieve consumer satisfaction in terms of quality and cost. (Hee et al., 2019) is a set of values and beliefs aimed at developing the company's business and improving its services while achieving a competitive advantage while ALmansour (2012) Reduce the time and dispense with all the tasks and activities that are useless and unnecessary for the customer as well as reducing the cost $\mathrm{FH}$ and raise the level of quality at all stages of production.

The application of the comprehensive quality in the system of production on time all the operations and activities of the economic unit through the adoption of all methods and techniques that contribute to increase productivity and dispense with all unnecessary activities and raise the level of quality in all stages of production. Focusing on the knowledge of the needs of customers and the supply of raw materials necessary for the production process according to the specifications and standards required to produce goods and crumbs meet those needs and contribute to enhancing the competitiveness of the company (Krajewski et al., 2013). The characteristics and characteristics of total quality are key features of the production system in a timely manner and the relationship between them is a complementary relationship aimed at improving and continuous development in the performance of companies to raise efficiency and create value added distinguish them from other companies by meeting all the needs of their customers of goods and services in time, Required.

\section{Flow Control Products (Kanban)}

In the production system at the specified time, the flow of products is controlled by the pull method as the demand pulls the production and output, which is allowed to be produced or not paid to the second workstation, except after the motion card which represents the demand is returned, where 
no part can be produced without the production card which permits it and cannot be moved The system originated in Toyota Motor Corporation and was named as the production system on time in the seventies of the last century by the early researchers, but this erroneous label was later replaced by The system is a simple information system used by the work center within the company to contact the Lord in order to supply an order of a material and processing another order of the same material. The second type is the movement card which allows movement of the boxes from the previous work station to the movement of the subsequent work. The application of the Kanban system contributes to achieving many advantages. It helps to reduce the minimum stock and improve productivity by following all production lines and quickly solving any problem facing production, discovering defective parts and units, reducing damage and loss of production process. In order to take advantage of these advantages (Krajewski et al., 2013) pointed to a number of conditions that must be met for the success of this system, as follows:

1.The number of cards should be a little, as the quantity of the stock is determined by the number.

2.The quantity of the following materials shall be withdrawn for production according to what is specified in the card without increasing or decreasing.

3.The previous stage is to produce the same quantity as the next stage, and the production is after receiving the cards with the relationship.

\section{Determines the Production System on Time (JIT)}

In spite of the benefits and advantages achieved by the application of the production system on time, it faces a number of limitations and constraints. These benefits and advantages vary according to the nature of the company and the environment in which it is applied and the availability of the necessary components for implementing this system. To some determinants of the JIT application, summarized by managers from the following point of view:

1. Not sure the speed and efficiency of the system

2. Difficulty tracking raw materials during operations

3. Not supporting suppliers of the company to switch to this system

4. Acquiring the administration in the current traditional methods and not having to transfer

5. Non-economic system in small-sized companies

(Shokory et al., 2019; Schenker et al., 2017) refers to another set of determinants that affect the application of the production system on time, including the following:

Cultural differences are considered one of the determinants of different cultures of individuals and different philosophy of employees in the company that affect the success of the production system on time may be difficult to change easily. Traditional methods depend on the presence of stocks in large quantities sometimes to face any potential increase in demand The application of the production system on time requires high qualifications by the employees of the company, which may not be available in some companies Lack of awareness and awareness of some individuals working in some companies to develop and resist any change that may occur in the company The reluctance of some senior departments to involve company employees in making decisions The efficiency and effectiveness of the production system on time varies according to the activity and nature of the company's work may be applied in the industrial company more efficient than the service company. 
Achieving the goals of the production system in a timely manner and taking advantage of its advantages may take a long time, which is considered an obligation to some departments that wish to obtain these features shortly. The researcher believes that each system or style of its advantages or specificities where rarely is available system can be considered appropriate for all companies Each company has its characteristics that must be taken into account and therefore vary the importance of this system and the importance of application to the size of the company and its ability to meet the needs of its customers, and the ability to provide materials in quantity And the degree of accuracy required as well as in its ability to develop the employees and their productive capacity. Therefore, despite the existence of the determinants of the system, however, if the ability is available by the company in working to provide the necessary elements for the implementation of that system and the required degree, Drakha the importance of developing innovation and the importance of staff development in Alharkh the application of the system will achieve its many advantages which will be reflected positively on the performance.

\section{Study Results}

\section{Reliability, Descriptive Statistics and Correlation Coefficient}

The present study utilized Cronbach's Alpha to ensure reliability and consistency of the final scales on the study variables as recommended by Pallant (2011). Table 1 indicates that the Cronbach's Alpha values range from .86 to .91 and they are statistically acceptable in both administrative and behavioral studies as they are above the value of 0.70 , indicating their internal consistency and reliability (Pallant, 2011). Descriptive statistics analysis is used to treat, describe and transform preliminary data into mini-numbers and models in a way that they represent the results to the larger community (See Table 1).

Table 1. Descriptive Statistics

\begin{tabular}{|l|l|l|l|l|l|l|}
\hline \multicolumn{1}{|l|}{ Mean } & Std. Deviation & $\mathrm{Jl}$ & $\mathrm{CO}$ & & \\
\hline $\mathrm{JI}$ & 3.34 & .86 & 1 & & & \\
\hline $\mathrm{CO}$ & 2.67 & .91 & $.52^{* *}$ & 1 & & \\
\hline Note: $\mathrm{N}=201$. Alpha reliabilities appear in parentheses. \\
$\mathrm{Jl}=\mathrm{JIT}, \mathrm{CO}=$ Cost \\
$*$. Correlation is significant at the 0.05 level (2-tailed). \\
$* *$. Correlation is significant at the 0.01 level (2-tailed).
\end{tabular}

\section{Hypotheses Testing}

This study examined the effects (direct and indirect) among the study variables and the proposed hypotheses were tested by conducting a path analysis using AMOS, version 20 (see Table 2 for results).

Table 2. Testing of hypotheses

\begin{tabular}{|l|l|l|l|l|l|l|}
\hline \multicolumn{2}{|l|}{ Path } & Direct Effect & S.E. & C.R. & P \\
\hline JIT & $\begin{array}{l}--- \\
>\end{array}$ & $\begin{array}{l}\text { Cos } \\
\mathrm{t}\end{array}$ & .290 & .002 & 3.389 & .001 \\
\hline
\end{tabular}




\section{Discussion of Results}

The research discussed production on time and its role in reducing costs. The research found that there is a direct impact of production on time on costs, and therefore on-time production helps to sustain the company by reducing costs. This impact reflects the company's role in promoting agile systems that help reduce waste by recycling waste and dealing with environmentally friendly products. This result indicates the significant role that production plays in the time of the company through its major role in the continuous improvement through the recycling and renewal and maintenance of the productive parts in profit for the developers, financiers and the owners of the company through the creation of jobs that lead to increased return on investment. As well as strengthening the company's health and safety of employees and the community. It is necessary to spread the culture and awareness of the special and integrated systems graceful among customers and employees to benefit from the promise of a method of work necessary to achieve profits and reduce costs and for this purpose it is necessary to balance between economic development and environmental protection and social justice and create coordination between sustainable industrialization and industrial scenario to achieve the desired goal Profits and increase the material return while not neglecting the right of society to maintain a healthy environment free of pollution and increase the green spaces and provide job opportunities. This is achieved by having a sustainable strategy that gives the plant flexibility in meeting the needs of future generations through innovation, repositioning, and proactive strategic planning.

\section{Conclusion}

Current results indicate that the company's management perceptions of a production system on time that may be represented by several concepts (eg agile systems and continuous improvement) will have a particular impact on the results of the manufacturing process, including sustainable manufacturing. Consequently, this can affect the dynamic processes of environmental sustainability, which in turn affects the environmental, social and economic performance of the company, generating significant returns for the company and reducing costs.

The best work of continuous improvement is that which begins from the worker through training, educating, refining his skills, and preparing him for more important work. And thus can be trusted and proposals submitted to the Department, especially those proposals related to the problems of work and lines of production and machines managed by himself. Thus becoming able to participate in several important processes such as product development and improvement of production methods.

While continuous improvement involves incremental changes whose effects can be seen in the short term, they lead to significant long-term contributions. To achieve continuous improvement, senior management must be supported and a long-term view is essential. It also requires the participation of all staff in the organization. The organization should also adopt the necessary supporting and necessary supporting structures related to training, management, distribution of resources, standards, reward system and incentives to motivate employees to accept continuous improvement as a way for the organization to achieve competitive advantages in the market.

It is well known that the organization's strategies reflect the importance of many measures to its performance. The most important and comprehensive measure is the time scale, which has become 
the most powerful source of competitive advantage for the leading companies in the market. This aspect usually involves reducing the production cycle time required to complete the process. Some industrial organizations use the short-cycle manufacturing cycle to describe their philosophy of continuously improving session time by eliminating losses. By default, organizations that achieve the shortest possible cycle times will accomplish tasks on time

\section{Theoretical and Contextual Contribution}

1. The immediate production system is one of the most advanced systems for planning and controlling production, and its application brings several benefits to the organization.

2. JIT aims to increase productivity, improve quality, reduce costs, and achieve customer satisfaction. 3. The system consists of a number of elements and basic elements without which the system can not work and can not reach its basic objectives, and these elements are grouped into three main groups are the deletion of loss, the involvement of everyone in the production process, and continuous improvement. Each group contains a number of important elements that all of them can achieve a successful implementation of the JIT system.

4. All of the above elements are the basic pillars of the JIT system. The success of the system depends not only on the availability of these elements, but also on the utilization and knowledge of how to manage, coordinate and direct them towards the desired objectives.

5. Some elements of JIT are key pillars of system implementation such as drag systems, Kanban card system, group technology, consolidation of relationship with processors.

6. Adapting the Iraqi manufacturing environment to the requirements of the current production system to facilitate its future implementation. For example, following the Kanban card system in production and procurement, dealing with one relative as much as possible to achieve the principle of reliability and reliability on the supplier.

7. Completion of the studies that have already been initiated in this field and conducting new studies and research aimed at identifying the obstacles that prevent the similarity between the environment of the Japanese industry and the Iraqi environment to diagnose them and work on removing them. The introduction of this system in the Iraqi environment in the future.

8. Follow-up training and qualification requirements for the cadres of Iraqi organizations in the field of this system, as well as attracting new cadres with high levels of scientific and administrative. This contributes to overcoming the state of decline and disintegration of these organizations.

\section{References}

Abdulaali, A. R., Alnoor, A. \& Eneizan, B. (2019), " A Multi-Level Study of Influence Knowledge Management Small and Medium Enterprises", Polish Journal of Management Studies, 10 (1), 21-31.

Abdulaali, A. R., (2018). The Impact of Intellectual Capital on Business Organization, Academy Of Accounting and Financial Studies Journal, 22 (6), 1-16.

Akomeah, E., Bentil, P., \& Musah, A. (2018). The Impact of Capital Structure Decisions on Firm Performance: The Case of Listed Non-Financial Institutions in Ghana. International Journal of Academic Research in Accounting, Finance and Management Sciences, 8(4), 1-15. 
INTERNATIONAL JOURNAL OF ACADEMIC RESEARCH IN BUSINESS AND SOCIAL SCIENCES

Vol. 9, No. 7, July, 2019, E-ISSN: 2222-6990 @ 2019 HRMARS

Al-Abrrow, H., Alnoor, A., \& Abbas, S. (2019). The effect of organizational resilience and CEO's narcissism on project success: Organizational risk as mediating variable. Organization Management Journal, 16 (1), 1-13.

Al-Abrrow, H., Alnoor, A., \& Abdullah, H. (2018). Socio-Technical Approach, Decision-Making Environment, and Sustainable Performance: Role of ERP Systems.Interdisciplinary Journal of Information, Knowledge, and Management, (13). 397-415 .

Al-Matarneh, G. F. (2012). Requirements and obstacles of using Just in Time (JIT) system: evidence from jordan. International Management Review, 8(1), 55.

Alnoor, A., Eneizan, B., Makhamreh, H. Z., Rahoma, I. A. (2019). The Effect of Reverse Logistics on Sustainable Manufacturing, International Journal of Academic Research in Accounting, Finance and Management Sciences 9 (1): 71-79

Amoako, K. O., Marfo, E. O., Gyabaah, E. N., \& Owiredu-Ghorman, K. (2017). Achieving a Sustainable Business: The Role of Environmental Management Accounting in Corporate Governance. International Journal of Academic Research in Accounting, Finance and Management Sciences, 7(4), 11-20.

Babagana, S. A., Mat, N. B., \& Ibrahim, H. B. (2019). Moderating Effect of Employee Participation on Factors that Determine Effective Performance Appraisal (EPA): Data Screening and Preliminary Analysis. International Journal of Academic Research Business and Social Sciences, 9(4), 116134.

Butt, M., Waqas, A., Kausar, S. T., \& Amir, Z. (2019). The Effect of Capacity Management Strategies on Employees' Well-Being of Public Hospitals of Lahore, Pakistan. International Journal of Academic Research in Business and Social Sciences, 9(3), 239-250.

Eker, M., \& Pala, F. (2008). The effect of competition, just in time production and total quality management on the use of multiple performance measures: an empirical study. Journal of Economic \& Social Research, 10(1), 35-72.

Eneizan, B. M., \& Obaid, T. F. (2016). Prior research on green marketing and green marketing strategy: critical analysis. Singaporean Journal of Business, Economics and Management Studies, 51(3965), 1-19.

Eneizan, B. M., \& Wahab, K. A. (2016). Determining the Factors Influencing Use of Mobile Marketing by Industrial Firms: An Empirical Investigation of Jordanian Industrial Firms. Indian Journal of Computer Science, 1(1), 25-36.

Haddad, M. F., Alshannag, F. M., Eneizan, B., \& Odeh, M. H. (2019). Impact of the Jordanian Commercial Banks on Financing Small and Medium Enterprises in Jordan. International Journal of Academic Research in Business and Social Sciences, 9(3), 16-26.

Hee, O. C., Halim, M. A., Ping, L. L., Kowang, T. O., \& Fei, G. C. (2019). The Relationship between Human Resource Management Practices and Job Performance in the Courier Service Industry . International Journal of Academic Research in Business and Social Sciences, 9(3), 63-79.

Ho, L. A. (2008). What affects organizational performance? The linking of learning and knowledge management. Industrial Management \& Data Systems, 108(9), 1234-1254.

Husin, S. N. M. S., Muda, T. F. M. T., Aziz, S. A., Salleh, S. F., Ismail, S. K., \& 1, W. M. Y. W. C .(2019) . The Types and Factors of Subsistence-Giving From the Perspective of Shariah. International Journal of Academic Research Business and Social Sciences, 9(4), 89-103. 
INTERNATIONAL JOURNAL OF ACADEMIC RESEARCH IN BUSINESS AND SOCIAL SCIENCES

Vol. 9, No. 7, July, 2019, E-ISSN: 2222-6990 @ 2019 HRMARS

Kootanaee, J. A., Babu, K. N., \& Talari, H. (2013). Just-in-time manufacturing system: from introduction to implement. Nagendra and Talari, Hamid, Just-In-Time Manufacturing System: From Introduction to Implement (March 1, 2013).

Krajewski, L. J., Ritzman, L. P., \& Malhotra, M. K. (2013). Operations management: processes and supply chains (Vol. 1). New York, NY: Pearson.

Mamat, A., Ali, M. S., Omar, S. H. S., Abidin, Z. Z., Ahmad, A. B., \& Yabi, S. (2019). Literature Review on Concept of Tafakkur in Islamic Mysticism. International Journal of Academic Research Business and Social Sciences, 9(4), 44-53.

Pallant, J. (2010). SPSS survival manual, 4th. England: McGraw-Hill Education.

Schenker, S., Vierhaus, I., Borndörfer, R., Fügenschuh, A., \& Skutella, M. (2017). Optimisation Methods in Sustainable Manufacturing. In Sustainable Manufacturing (pp. 239-253). Springer International Publishing.

Shokory, S. M., Hamid, S. A., Awang, M., \& Hudin, N. S. (2019). The Impact of the Leadership of the Head of Department on Administrative Staff's Performance in Malaysian Premier Education University. International Journal of Academic Research in Business and Social Sciences, 9(3), 2742.

Singh, S., \& Garg, D. (2011). JIT system: concepts, benefits and motivation in Indian industries.

Thürer, M., Stevenson, M., Silva, C., Land, M. J., Fredendall, L. D., \& Melnyk, S. A. (2014). Lean control for make-to-order companies: Integrating customer enquiry management and order release. Production and Operations Management, 23(3), 463-476.

Zikmund, W. G., Babin, B. J., Carr, J. C., \& Griffin, M. (2013). Business research methods. Cengage Learning. 